This item was submitted to Loughborough's Research Repository by the author.

Items in Figshare are protected by copyright, with all rights reserved, unless otherwise indicated.

\title{
Understanding design change propagation in complex engineering systems using a digital twin and design structure matrix
}

\author{
PLEASE CITE THE PUBLISHED VERSION
}

https://doi.org/10.1108/ecam-08-2020-0615

\section{PUBLISHER}

Emerald

\section{VERSION}

AM (Accepted Manuscript)

\section{PUBLISHER STATEMENT}

This paper was accepted for publication in the journal Engineering, Construction and Architectural Management and the definitive published version is available at https://doi.org/10.1108/ecam-08-2020-0615. This author accepted manuscript is deposited under a Creative Commons Attribution Non-commercial 4.0 International (CC BY-NC) licence. This means that anyone may distribute, adapt, and build upon the work for non-commercial purposes, subject to full attribution. If you wish to use this manuscript for commercial purposes, please contact permissions@emerald.com

\section{LICENCE}

CC BY-NC 4.0

\section{REPOSITORY RECORD}

Chen, Long, and Jennifer Whyte. 2021. "Understanding Design Change Propagation in Complex Engineering Systems Using a Digital Twin and Design Structure Matrix". Loughborough University. https://hdl.handle.net/2134/15097755.v1. 

using a Digital Twin and Design Structure Matrix

5 ABSTRACT

6 Purpose

7 As the engineering design process becomes increasingly complex, multidisciplinary teams need to

8 work together, integrating diverse expertise across a range of disciplinary models. Where changes arise, 9 these design teams often find it difficult to handle these design changes due to the complexity and 10 interdependencies inherent in engineering systems. This paper aims to develop an innovative approach 11 to clarifying system interdependencies and predicting the design change propagation at the asset level

12 in complex engineering systems based on the digital-twin-driven design structure matrix (DSM).

\section{Design/methodology/approach}

14 The paper first defines the digital-twin-driven DSM in terms of elements and interdependencies, where 15 we have defined three types of interdependency, namely, geospatial, physical and logical at the asset 16 level. The digital twin model was then used to generate the large-scale DSMs of complex engineering 17 systems. The cluster analysis was further conducted based on the improved Idicula-Gutierrez-Thebeau 18 Algorithm (IGTA-Plus) to decompose such DSMs into modules for the convenience and efficiency of 19 predicting design change propagation. Finally, a design change propagation prediction method based 20 on the digital-twin-driven DSM has been developed by integrating the change prediction method 21 (CPM), a load-capacity model and fuzzy linguistics. A section of an infrastructure mega-project in 22 London was selected as a case study to illustrate and validate the developed approach.

\section{Findings}

24 The digital-twin-driven DSM has been formally defined by the spatial algebra and Industry Foundation 25 Classes (IFC) schema. Based on the definitions, an innovative approach has been further developed to 26 (1) automatically generate a digital-twin-driven DSM through the use of IFC files, (2) to decompose 27 these large-scale DSMs into modules through the use of IGTA-Plus, and (3) predict the design change 28 propagation by integrating a digital-twin-driven DSM, CPM, a load-capacity model and fuzzy 29 linguistics. From the case study, the results showed that the developed approach can help designers to 30 predict and manage design changes quantitatively and conveniently.

\section{Originality/value}


32 This research contributes to a new perspective of the DSM and digital twin for design change 33 management and can be beneficial to assist designers in making reasonable decisions when changing

34 the designs of complex engineering systems.

35 Keywords: Digital twin; Design structure matrix; Design change propagation

\section{$36 \quad 1$ Introduction}

37 Through a series of infrastructure projects and programmes including those at Heathrow, London, the 382012 Olympics, Crossrail, Tideway and High-Speed 2 (HS2), the UK is developing significant 39 expertise in the delivery of major infrastructure projects (Whyte, 2019; Davies, 2017). To address the 40 challenges of infrastructure delivery, multidisciplinary teams work together, integrating diverse 41 expertise across disciplines. One challenge that arises is that design teams find it difficult to understand 42 the impacts of late design changes in such complex engineering systems (e.g. infrastructures), where 43 changes in one sub-system may have implications for other systems (Whyte et al., 2016). While there 44 is ongoing interest in systems integration in large projects, there is a need to articulate the complexity 45 of and interdependencies found in such systems to understand the design change propagation and its 46 impacts.

47 Previous efforts have been made to identify system interdependencies and trace design changes of 48 complex infrastructures. Eusgeld et al. (2011) proposed a 'system-of-systems' approach to identify and 49 analyse interdependencies between industrial control systems (ICS). Goldbeck et al. (2019) developed 50 a new, effect-based classification of interdependencies between infrastructure systems. The Design 51 Structure Matrix (DSM) is a matrix showing interdependencies between components in the system 52 (Browning, 2001). With the increasing complexity of infrastructures, it has become used as a simple, 53 compact and visual representation of a complex system. It has been adopted widely to model and 54 analyse the product decomposition and interdependencies (Pimmler and Eppinger, 1994), to show data 55 interdependencies in the multidisciplinary design process (Lambe and Martins, 2012), to formulate the 56 interdependencies between drawings of physical components at the lowest level of abstraction in 57 construction design (Senthilkumar and Varghese, 2009), and to predict and manage design changes in 58 complex engineering systems (Clarkson et al., 2004; Fu et al., 2012).

59 While data consistency and quality have traditionally been relatively poor, such complex engineering 60 systems are becoming rich sources of data deriving from multidisciplinary models and systems (Whyte 61 et al., 2016), raising new opportunities to understand the interdependencies and model design change 62 propagation in the design of new infrastructures. However, current DSM methods are inefficient in 63 handling design changes with a large number of elements and the complex interdependencies of 
64 increasingly integrated and expanded complex engineering systems. There is a need to develop a new 65 method applicable to complex engineering systems which can not only generate the large-scale DSMs conveniently but analyse the design change propagation risk reliably.

67 The development of digital technologies, especially Building Information Modelling (BIM) and digital twin techniques, provides a way to transfer complex engineering systems into the digital built environment, which enables the identification of complex building components and interdependencies digitally and automatically. The IFC functioning as a standard representation of BIM knowledge for interoperability further opens the possibility to integrate DSM with digital data for more convenient identification of system interdependencies and more effective design change management. Inspired by the interoperability of the IFC schema, Pektas (2010) proposed the complementary integration of IFC process modelling (e.g. IDEF0) and a parameter-based DSM in modelling the collaborative building design process. Jacob and Varghese (2011) proposed a logic of integration of BIM and DSM to improve construction design processes through the definition of new classes 'IfcDSM' and 'IfcConnectsByInformation'. Based on that, Jacob and Varghese (2012) made further efforts to handle design process complexity, derived from the increased sophistication of product models through an integrating process model (e.g. IFC process model and DSM) with a product model (i.e. IFC product model). However, these efforts were mainly premised on the hypothesis of potential IFC extensions (e.g. IfcDSM) and were limited to activity-/parameter-based DSM. Gopsill et al. (2016) succeeded in automatically generating a component-based DSM by monitoring the design changes in the digital models representing products. Saoud et al. (2017) proposed the integration of a parameter-based DSM with BIM to predict change propagation of design parameters within the BIM model. Although these efforts have succeeded in generating component-based or design parameter-based DSMs for predicting design change propagation, the work of Gopsill et al. (2016) is found to be inadequate for clarifying and classifying different kinds of interdependencies between elements in a DSM, and the work of Saoud et al. (2017) only focused on the spatial and analytical interdependencies for predicting and visualising design change propagation. There is still a need to develop an approach for predicting design change propagation based on a digital-twin-driven DSM with comprehensive system interdependencies identified.

This research aims to develop an innovative approach to clarifying system interdependencies to predict change propagation in complex engineering systems at the asset level based on the digital-twin-driven DSM. Drawing on the literature review, this research first defined the digital-twin-driven DSM in terms of elements and interdependencies. The IFC files from a digital twin model were then used to generate the large-scale DSMs of complex engineering systems. Cluster analysis was further 
97 conducted based on the IGTA-Plus to decompose such DSMs into modules for the convenience and

98 efficiency of predicting design change propagation. Finally, a design change propagation prediction

99 method based on the digital-twin-driven DSM was developed by integrating the CPM, a load-capacity

100 model and fuzzy linguistics. A tunnel section of an infrastructure mega-project in London was selected

101 as a case study to illustrate and validate the developed approach.

102 The structure of the paper is organised as follows: We define the key concepts and clarify their 103 relationships in section 2; The research methodology is set out in section 3; The development and 104 modularity of digital-twin-driven DSM are introduced in section 4; Section 5 develops the design 105 change propagation prediction method based on a digital-twin-driven DSM; Section 6 introduces the 106 implementation of the developed approach in a case study; Section 7 is the discussion and conclusions 107 are in section 8 .

\section{2. Background}

\subsection{System interdependencies in complex engineering systems}

110 Complex engineering systems are characterised by having a large number of dimensions, non-linear 111 models, strong interactions, unknown or inherently random plant parameters and time delays in the 112 dynamical structure (Jamshidi, 1996; Eusgeld et al., 2011). Many modern engineering projects are 113 large complex engineering systems within dynamic environments, which usually comprise a large 114 number of interacting sub-systems for components, processes, activities, stakeholders, resources and 115 information (Abdoli and Kara, 2020; Zhu and Mostafavi, 2017). As shown in Table 1, these complex 116 engineering systems can be divided into four levels based on the unified classification from Uniclass, 117 namely, the system-of-systems, system, sub-system and asset levels (Pimmler and Eppinger, 1994; 118 Senthilkumar and Varghese, 2009; Chou and Tseng, 2010; Eusgeld et al., 2011; Delany, 2019).

119 The design of such complex engineering systems is very challenging due to complex system 120 interdependencies among or within systems and with external environments (Li, 2018). These system 121 interdependencies can be defined as bi-directional or uni-directional relationships at different levels 122 where the output of one item is essential to the input of another (Rinaldi et al., 2001; Zimmerman, 123 2001). For example, interdependency exists between a water pumping station and an electricity 124 substation providing electricity for it (Holden et al., 2013). Another kind of system interdependency 125 also exists between the water pumping station and a sewer tunnel which transports the sewage from 126 the pumping station (Whyte et al., 2019).

127 Table 1 Decomposition of complex engineering systems

\begin{tabular}{|c|c|c|c|c|}
\hline Level & Sub-level & Definition & Example & References \\
\hline
\end{tabular}




\begin{tabular}{|c|c|c|c|c|}
\hline \multicolumn{2}{|c|}{ System-of-systems } & $\begin{array}{l}\text { Assembly of multiple, } \\
\text { heterogeneous, distributed, } \\
\text { occasionally independently } \\
\text { operating systems embedded } \\
\text { in networks at multiple levels }\end{array}$ & $\begin{array}{ll}\text { - } & \text { National infrastructure } \\
& \text { scheme } \\
\text { - } & \text { Smart city } \\
\text { - } & \text { Community } \\
\text { - } & \text { Space exploration etc. }\end{array}$ & $\begin{array}{l}\text { Zhang and Peeta, 2011; } \\
\text { Eusgeld et al., 2011; } \\
\text { Chen and Whyte, } 2020 .\end{array}$ \\
\hline \multicolumn{2}{|c|}{ System } & $\begin{array}{l}\text { Assembly of physical sub- } \\
\text { systems for high-level } \\
\text { functions }\end{array}$ & $\begin{array}{l}\text { - Transportation engineering } \\
\text { system: Airport, railway etc. } \\
\text { - Water engineering system: } \\
\text { sewer etc. }\end{array}$ & $\begin{array}{l}\text { Pimmler and Eppinger, } \\
\text { 1994; Rinaldi et al., } \\
\text { 2001; Senthilkumar } \\
\text { and Varghese, 2009; } \\
\text { Chou and Tseng, 2010; } \\
\text { Eusgeld et al., 2011. }\end{array}$ \\
\hline \multicolumn{2}{|c|}{ Sub-system } & $\begin{array}{l}\text { Geographically distinct entity } \\
\text { created to meet specific high- } \\
\text { level functions for the users of } \\
\text { the system. }\end{array}$ & $\begin{array}{l}\text { Terminal building or station } \\
\text { in transportation engineering } \\
\text { system } \\
\text { - Pumping station, tank and } \\
\text { tunnel section etc. in water } \\
\text { engineering system }\end{array}$ & $\begin{array}{l}\text { Pimmler and Eppinger, } \\
\text { 1994; Eusgeld et al., } \\
\text { 2011; Heracleous et al., } \\
\text { 2017; Chen and Whyte, } \\
\text { 2020. }\end{array}$ \\
\hline \multirow[t]{2}{*}{ Asset } & Section & $\begin{array}{l}\text { Physical entity created to meet } \\
\text { specific functions for the } \\
\text { system. }\end{array}$ & $\begin{array}{ll}\text { - } & \text { Architecture } \\
\text { - } & \text { Structure } \\
\text { - } & \text { MEP } \\
\text { - } & \text { HVAC etc. }\end{array}$ & $\begin{array}{l}\text { Senthilkumar and } \\
\text { Varghese, 2009; Chou } \\
\text { and Tseng, 2010. }\end{array}$ \\
\hline & Component & $\begin{array}{l}\text { Physical entity with specific } \\
\text { functions in each section. }\end{array}$ & $\begin{array}{l}\text { - } \text { Duct } \\
\text { - } \text { Beam } \\
\text { - Column } \\
\text { - Foundation pile etc. }\end{array}$ & $\begin{array}{l}\text { Pimmler and Eppinger, } \\
\text { 1994; Senthilkumar } \\
\text { and Varghese, 2009; } \\
\text { Chou and Tseng, 2010; } \\
\text { Saoud et al., 2017; } \\
\text { Chen and Whyte, } 2020 .\end{array}$ \\
\hline
\end{tabular}

129 Infrastructure projects are complex engineering systems in which large sets of components are brought 130 together and interact with one another. Each component of infrastructure constitutes a small part of the 131 intricate web that forms the overall infrastructure (Rinaldi et al., 2001). This complexity exhibited by 132 infrastructure as a whole is beyond the simple aggregation of its components and should be 133 investigated by clarifying the system interdependencies of infrastructures (Chen et al., 2020). For 134 instance, Rinaldi et al. (2001) identified four types of system interdependency between infrastructure 135 systems, including physical, cyber, geographic and logical. Mendonça and Wallace (2006) focused on 136 service and space connections and also defined four categories of system interdependency, namely 137 input, shared, exclusive-or, and co-location. Eusgeld et al. (2011) extended the aforementioned insights 138 and looked at different system interdependencies in more detail, where nine types of system 139 interdependency have been identified, including input, mutual, co-located, shared, exclusive-or, 140 physical, cyber, geographic, and logical. Most of the previous works focused on the system or sub141 system levels while the system interdependencies at the asset level were rarely explored which, 142 however, are significant for the delivery and service provision of infrastructures (Table 2). Although 143 Saoud et al. (2017) identified spatial and analytical interdependencies at the asset level, it is still 144 necessary to identify the system interdependencies at the asset level more comprehensively and 145 systematically. 
146 Table 2 System interdependencies identified in previous works

\begin{tabular}{|c|c|c|}
\hline Level & Identified system interdependencies & References \\
\hline \multirow[t]{7}{*}{ System } & Four types of interdependency, including physical, cyber, geographic, and logical. & $\begin{array}{l}\text { Rinaldi et al., } \\
2001\end{array}$ \\
\hline & Two types of interdependency, including functional and spatial. & $\begin{array}{l}\text { Zimmerman, } \\
2001\end{array}$ \\
\hline & $\begin{array}{l}\text { Four interdependent conditions defined, including input, shared, exclusive-or, and } \\
\text { colocation. }\end{array}$ & $\begin{array}{l}\text { Mendonça and } \\
\text { Wallace, } 2006\end{array}$ \\
\hline & $\begin{array}{l}\text { Five types of interdependency, including physical, informational, geospatial, } \\
\text { procedural and societal. }\end{array}$ & $\begin{array}{l}\text { Dudenhoeffer et } \\
\text { al., } 2007\end{array}$ \\
\hline & Four types of interdependency, including functional, physical, budgetary, market & $\begin{array}{l}\text { Zhang and Peeta, } \\
2011\end{array}$ \\
\hline & and economic. & \\
\hline & $\begin{array}{l}\text { Two categories of interdependency, including location-specific (physical), and } \\
\text { functional. }\end{array}$ & Utne et al., 2011 \\
\hline \multirow[t]{3}{*}{$\begin{array}{l}\text { System \& } \\
\text { sub-system }\end{array}$} & $\begin{array}{l}\text { Nine categories of interdependency, including input, mutual, co-located, shared, } \\
\text { exclusive-or, physical, cyber, geographic, and logical. }\end{array}$ & $\begin{array}{l}\text { Eusgeld et al., } \\
2011\end{array}$ \\
\hline & $\begin{array}{l}\text { Two kinds of interdependency defined, including internal and external, where the } \\
\text { external interdependencies were further represented by physical, cyber, geographic, } \\
\text { and logical. }\end{array}$ & $\begin{array}{l}\text { Heracleous et al., } \\
2017\end{array}$ \\
\hline & $\begin{array}{l}\text { Four types of interdependency, including stochastic failure propagation, logic, asset } \\
\text { utilisation, and resource input. }\end{array}$ & $\begin{array}{l}\text { Goldbeck et al., } \\
2019\end{array}$ \\
\hline Asset & $\begin{array}{l}\text { Two kinds of interdependency defined with BIM, including spatial and analytical } \\
\text { interdependencies. }\end{array}$ & $\begin{array}{l}\text { Saoud et al., } \\
2017\end{array}$ \\
\hline
\end{tabular}

148 Within the context of the above complex system interdependencies, different approaches have been 149 proposed to represent and visualise system interdependencies. Utne et al. (2011) adopted the cascade 150 diagram to show interdependencies between critical infrastructures, which was useful to quantify the 151 system interdependencies but ignored the bidirectional ones and did not leverage the network and 152 spatial characteristics of infrastructures (Zhang and Peeta, 2011).

153 To address this limitation, many efforts have been made based on network-based approaches. For 154 instance, Jeong et al. (2006) developed a network-based model to show interdependencies at the sub155 system level in water systems, which were composed of a plant, transmission pipelines, storage 156 stations, and distribution lines. Wang et al. (2012) developed a network-based model for representing 157 and analysing topological interdependencies between power and water systems. Based on these, Zhang 158 and Peeta (2011) developed a multilayer infrastructure network framework to model infrastructure 159 interdependencies, where individual infrastructure systems were represented as network layers and 160 system interdependencies were represented as links within and across network layers. Using this 161 framework, Holden et al. (2013) and Goldbeck et al. (2019) proposed a network flow model for 162 interdependent infrastructures, which consisted of a set of directed edges representing 163 interdependencies and vertices indicating general multi-functional infrastructure systems or sub164 systems. Eusgeld et al. (2011) adopted a "system-of-systems" architecture to describe the 
interdependencies between the supervisory control and data acquisition (SCADA) and the system under control ( $\mathrm{SuC}$ ) including the electric power supply system and the gas supply system. However, the granularity of these network-based models was not suitable to describe system interdependencies at an asset level, nor sufficiently efficient to perform functional analysis (Eusgeld et al., 2011; Heracleous et al., 2017).

170 Some software has also been developed and applied to the identification and visualisation of system 171 interdependencies at the asset level, such as Solibri, BIM 360 and Navisworks, which is convenient 172 for analysing spatial interdependencies through clash detection and is becoming popular among 173 designers due to the straightforward 3D visualisation. However, they are not capable of the holistic 174 "what-if" analysis of design changes (Zhang and Peeta, 2011). The matrix structure has been further 175 employed by Mendonça and Wallace (2006) and Saoud et al. (2017) to create "what-if" scenarios for 176 interdependency analysis, raising new opportunities to improve the performance of the software by 177 combining it with the matrix structure.

\section{$178 \quad 2.2$ Design change propagation via system interdependencies}

179 Change is common in project delivery processes, with design changes arising to improve the 180 performance of projects or to address newly emerged requirements (Eckert et al., 2004). Yet it is costly, 181 with changes and rework activities having a significant impact on the project delivery schedule, cost 182 and quality (Ma et al., 2017). It is, thus, necessary to manage design changes properly. The system 183 interdependencies in complex engineering systems have a major impact on design change management, 184 where changes to one part of such systems may induce a change to another part via system 185 interdependencies. The greater the interdependencies between parts, the larger the chance that a change 186 to one part spreads to others. A change, thus, rarely occurs alone, and multiple changes can have 187 interacting effects on other elements of the system (Eckert et al., 2004). Understanding how and why 188 changes propagate during the design process is critical for the design change management of complex 189 engineering systems (Giffin et al., 2009; Pasqual and de Weck, 2012).

190 In this research, the design change propagation is defined as a process "by which a change to one part or element of an existing system or product configuration or design results in one or more additional changes to the system, when those changes would not have otherwise been required" (Giffin et al., 2009). Change propagation occurs due to the interdependencies between the sub-systems or assets of complex engineering systems (Pasqual and de Weck, 2012). Eckert et al. (2004) distinguished between two types of design change with change propagation behaviour taken into account, namely, initiated change and emergent change. The initiated change usually arises from new requirements and needs, 
changing because of errors or undesirable emergent system properties, often due to an earlier initiated change. Based on that, the authors further provided the basic framework for classifying change propagation effects within a certain time frame, including ripple, blossom and avalanche, where the former two are predictable and can be contained within the expected duration while the last one is unpredictable and can become completely out of control (Eckert et al., 2004; Li et al., 2020).

203 To mitigate small changes propagating and becoming an undesirable avalanche of changes, multiple methods of predicting the design change propagation risk have been developed, which assess the risk in terms of propagation probability and the impact of change for each component. For instance, Isaac and Navon (2013) developed a graph-based model to detect the impact of a proposed design change, and they also adopted a clustering algorithm to identify directly affected components and a path-search algorithm to identify the indirect impact on the project. Lee and Hong (2017) developed a Bayesian approach to change propagation analysis. Lee et al. (2010) used the analytic network process (ANP) to measure the relative importance of parts and modules in a modular product in terms of design change impacts and propagation. Kocar and Akgunduz (2010) employed sequential pattern mining techniques to process captured engineering change history for a virtual engineering change management solution. However, these approaches cannot accommodate feedback and iterations that are commonly extant in the design of complex engineering systems. Recent studies pay more attention to network-based methods because complex engineering systems are more readily modelled as networks (Pasqual and de Weck, 2012; Li et al., 2020). For instance, Fu et al. (2012) established a network-based model to predict the risk of change propagation and thereby optimise module organisation. Li et al. (2020) proposed multilayer networks with a product layer and an organisation layer to reveal the law of design change risk propagation and mitigate the disruptive design change risk. The network-based methods can effectively represent and analyse the interdependencies in and between different elements in complex engineering systems, which have been thus applied to this research to predict and analyse the design change propagation risk.

\subsection{A design structure matrix for design change propagation}

224 The DSM has been the most widely adopted network-based method and provides a simple, compact, 225 and visual representation of complex engineering systems that is effective in addressing decomposition 226 and integration problems, and managing iterative tasks (e.g. design process). A DSM is a square matrix $227\left(N^{2}\right)$ with identical row and column labels, where an off-diagonal mark ('cross' in Figure 1) signifies 228 the dependency of one element on another. Reading across a row indicates input sources while reading 229 down a column reveals sinking outputs. In Figure 1, element B provides something to or is related to 230 element $\mathrm{E}$, and it depends on something from or relates to element A (Browning, 2001). 


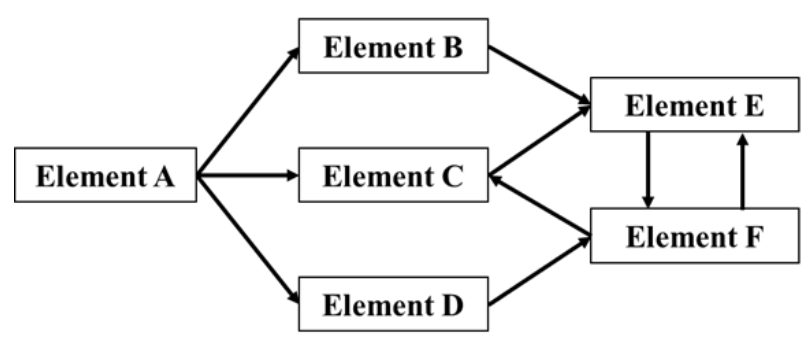

233 There are four main categories of DSM in applications (Browning, 1999, 2001). These are (1) 234 Component-based or an architecture DSM, which is used for modelling system architectures based on 235 236

Figure 1. Related elements and the representation of interdependencies in DSM components and/or sub-systems and their relationships; (2) Team-based or organisation DSM, which is used for modelling organisation structures based on people and/or groups and their interactions; (3) Activity-based or schedule DSM, which is used for modelling processes and activity networks based on activities and their information flow and other dependencies; and (4) Parameter-based or low-level schedule DSM: which is used for modelling low-level relationships between design decisions and parameters, systems of equations, subroutine parameter exchanges etc. (Table 3 ).

The use of DSM in analysing and managing project designs has been increasing, especially in the design change management of complex engineering systems, where the development of such DSM is based on either knowledge-driven methods, data-driven methods, or digitally-driven methods (Table 3).

The majority of DSM-related studies are based the knowledge-driven methods, which leveraged expert opinions from design documents and interviews when identifying the system elements and interdependencies. For example, Clarkson et al. (2004) developed the CPM-based DSM which estimated the combined risk of change propagation by quantifying both the likelihood and impact of design changes by interviewing designers. Li et al. (2020) mapped the complex product development projects into multilayer DSMs with product layers and organisation layers based on multilayer network theory and built the model of design change risk propagation based on DSM and load-capacity model. Although the knowledge-driven methods are flexible to generate DSMs for different purposes, they are labour intensive and time-consuming when dealing with a large-scale DSM. For instance, it took five months to construct the $462^{2}$ NASA pathfinder DSM (Brady, 2002).

Data-driven methods made use of historical design record to identify co-changing relationships and probability. For example, Giffin et al. (2009) used data mining to process 41,500 change requests for 
257 constructing a change network. Similarly, Gopsill et al. (2016) developed an automatic generation 258 method for DSM by monitoring the design changes in the digital models representing the product. 259 These methods are efficient in generating DSMs from large datasets, but they are lacking in a 260 systematic view of system elements and interdependencies.

261 Digitally-driven methods have been proposed recently to make full use of digital information (e.g. 262 BIM and IFC files) from complex engineering systems. Jacob and Varghese (2011) defined a new IFC 263 class 'IfcDSM' and proposed to generate a DSM using object parameters and relationships from IFC 264 model files. They further proposed a DSM-based framework to integrate the information from the 265 product, design process, and design teams by using IFC files and manually pre-defined rules (Jacob 266 and Varghese, 2012, 2018). Saoud et al. (2017) integrated a parameter-based DSM with BIM to predict 267 the change propagation of design parameters. These pioneering works are time-saving and can clarify 268 system elements and interdependencies, but they only focused on design sequences or specific spatial 269 and analytical interdependencies, lacking a comprehensive understanding of such elements and 270 interdependencies at different levels.

271 These DSM-based methods are inefficient to handle a large number of complex elements and 272 interdependencies for increasingly integrated and expanded complex engineering systems. There is a 273 need to develop a new DSM-based method that can both automatically generate a DSM 274 comprehensively and systematically and conveniently analyse design change propagation risk for 275 complex engineering systems.

276 Table 3. Example of DSM in design change management of complex engineering systems

\begin{tabular}{|c|c|c|c|c|}
\hline DSM Types & References & Elements of DSM & Interdependencies of DSM & Data Collection \\
\hline \multirow[t]{9}{*}{ Component-based } & Brady, 2002 & Technologies & Technology interface & $\begin{array}{l}\text { Knowledge- } \\
\text { driven }\end{array}$ \\
\hline & Clarkson et al., 2004 & $\begin{array}{l}\text { Product sub- } \\
\text { systems }\end{array}$ & $\begin{array}{l}\text { Design change propagation } \\
\text { risk }\end{array}$ & $\begin{array}{l}\text { Knowledge- } \\
\text { driven }\end{array}$ \\
\hline & $\begin{array}{l}\text { Senthilkumar and } \\
\text { Varghese, } 2009\end{array}$ & Drawings & Design issues of drawings & $\begin{array}{l}\text { Knowledge- } \\
\text { driven }\end{array}$ \\
\hline & Giffin et al., 2009 & Design areas & Design change propagation & Data-driven \\
\hline & Fu et al., 2012 & $\begin{array}{l}\text { Product } \\
\text { architectural } \\
\text { components }\end{array}$ & $\begin{array}{l}\text { Design change propagation } \\
\text { risk }\end{array}$ & $\begin{array}{l}\text { Knowledge- } \\
\text { driven }\end{array}$ \\
\hline & $\begin{array}{l}\text { Jacob and Varghese, } \\
2012\end{array}$ & $\begin{array}{l}\text { Building } \\
\text { components }\end{array}$ & Spatial dependencies & Digitally-driven \\
\hline & Colombo et al., 2015 & $\begin{array}{l}\text { Product } \\
\text { architectural } \\
\text { components }\end{array}$ & Component interfaces & Data-driven \\
\hline & Gopsill et al., 2016 & $\begin{array}{l}\text { Digital models (e.g. } \\
\left.\text { CAD, CFD, FEA }^{1}\right)\end{array}$ & $\begin{array}{l}\text { Component dependencies } \\
\text { across models }\end{array}$ & Data-driven \\
\hline & Li et al., 2020 & $\begin{array}{l}\text { Product } \\
\text { architectural } \\
\text { components }\end{array}$ & Inter-component interfaces & $\begin{array}{l}\text { Knowledge- } \\
\text { driven }\end{array}$ \\
\hline Team-based & Senthilkumar and & Design teams & Design interfaces between & Knowledge- \\
\hline
\end{tabular}




\begin{tabular}{|c|c|c|c|c|}
\hline & Varghese, 2009 & & teams & driven \\
\hline & Li et al., 2020 & Design teams & Inter-team iterations & $\begin{array}{l}\text { Knowledge- } \\
\text { driven }\end{array}$ \\
\hline \multirow[t]{3}{*}{ Activity-based } & Austin et al., 2000 & Design activities & $\begin{array}{l}\text { Design information } \\
\text { dependencies }\end{array}$ & $\begin{array}{l}\text { Knowledge- } \\
\text { driven }\end{array}$ \\
\hline & $\begin{array}{l}\text { Jacob and Varghese, } \\
2012\end{array}$ & Design activities & Design sequence & Digitally-driven \\
\hline & Prasad and Jacob, 2018 & Design activities & $\begin{array}{l}\text { Design information } \\
\text { dependencies }\end{array}$ & $\begin{array}{l}\text { Knowledge- } \\
\text { driven }\end{array}$ \\
\hline \multirow[t]{4}{*}{ Parameter-based } & Pektaş and Pultar, 2006 & $\begin{array}{l}\text { Design parameters } \\
\text { and requirements }\end{array}$ & Design information flows & $\begin{array}{l}\text { Knowledge- } \\
\text { driven }\end{array}$ \\
\hline & Pektas, 2010 & Design parameters & Design information flows & $\begin{array}{l}\text { Knowledge- } \\
\text { driven }\end{array}$ \\
\hline & $\begin{array}{l}\text { Jacob and Varghese, } \\
2011\end{array}$ & Design parameters & Spatial dependencies & Digitally-driven \\
\hline & Saoud et al., 2017 & $\begin{array}{l}\text { Design parameters } \\
\text { (geometry, position, } \\
\text { specification) }\end{array}$ & $\begin{array}{l}\text { Spatial and analytical } \\
\text { dependencies (in, inter, self, } \\
\text { join, host, s.host, s.sys }{ }^{2} \text { ) }\end{array}$ & $\begin{array}{l}\text { Digitally- } \\
\text { driven/Knowled } \\
\text { ge-driven }\end{array}$ \\
\hline Hybrid & $\begin{array}{l}\text { Jacob and Varghese, } \\
2018\end{array}$ & $\begin{array}{l}\text { Building } \\
\text { components, work } \\
\text { sets, design teams }\end{array}$ & $\begin{array}{l}\text { Spatial, temporal and } \\
\text { organisational dependencies }\end{array}$ & $\begin{array}{l}\text { Digitally- } \\
\text { driven/Knowled } \\
\text { ge-driven }\end{array}$ \\
\hline
\end{tabular}

277 Note: ${ }^{1}$ CAD: Computer-aided design; CFD: Computational fluid dynamics; FEA: Finite element analysis.

2782 in: elements belong to; inter: intersection between; self: relation within the same item; join: elements are connected to 279 each other; host: being the host element; s.host: two elements have the same host element; s.sys: elements are defined in 280 one system.

\subsection{Digital twin and IFC for system interdependencies}

282 As the wave of digitalisation is already here, infrastructures are becoming increasingly cyber283 physically integrated, being rich sources of data from multidisciplinary models and systems for 284 understanding complex interdependencies and design change propagation in complex engineering 285 systems (Whyte et al., 2016). At the heart of digitalisation, the digital twin was first proposed by 286 Michael Grieves in 2002 as the virtual representation of current physical products (Tchana et al., 2019).

287 Then the digital twin in infrastructure was further clarified as: "realistic digital representations of physical things. They unlock value by enabling improved insights that support better decisions, leading to better outcomes in the physical world" (Bolton et al. 2018). While the shift from computer-aided design (CAD) to Building Information Modelling (BIM) involved the addition of semantic information of infrastructure assets as well as geometry, the shift to a digital twin requires the use of a broader range of sources of data, which may involve geometries, asset information and associated time series data on processes. Such data may be generated through the activities of professionals, in production and operation, and through a range of sensing devices (including photographs, laser scans, and embedded sensors).

Currently, attention is being drawn to the use of flows of such digital information to identify specific system interdependencies of infrastructures for better decisions, outcomes and performance, which are mainly based on IFC. As a comprehensive international standard for information interoperability, IFC 
299 is developed and managed by building SMART. It is a set of definitions describing the consistent data 300 representation of building components for storing and exchanging building information over the whole 301 life cycle (Zhang and Issa, 2013). The IFC entities represent not only geometric information (e.g., 302 geometry representation and spatial topology) but also semantic properties, processes and relationships 303 (e.g., materials, fabrication, and ontology), thereby endowing the IFC entities with intelligence. Based 304 on the IFC schema, most current efforts have concentrated on developing semantic object-oriented 305 information models for clarifying specific system interdependencies of assets. For instance, Dibley et 306 al. (2012) captured the interdependencies of building and sensors by developing an ontology 307 framework. Zhang and Issa (2013) modelled and extracted the logical interdependencies of building 308 elements with a web ontology language (OWL) based on IFC specifications. Terkaj and Šojić (2015) 309 also defined the interdependencies between non-abstract subtypes of IfcObject and IfcTypeObject 310 using ifcOWL. However, these works are unable to interpret the geometric information including 311 spatial objects and interdependencies that are implicitly or explicitly contained in the digital models. 312 To fill this gap, Borrmann and Rank (2009) developed concepts and techniques for topological 313 operators for spatial topological analysis based on an octree-based algorithm. They further developed

314 a boundary representation based method for processing spatial topologies (Daum and Borrmann, 2014).

315 These efforts are beneficial in identifying and extracting specific system interdependencies, but they 316 cannot support the development of DSM with complex and multiple system interdependencies for 317 design change management of infrastructures. A new digital-twin-driven method is, thus, needed to be 318 developed for automatic DSM generation and analysis using the IFC schema, wherein both the 319 geometry information and the objectified relationships can be used for both spatial and non-spatial 320 interdependencies' identification of infrastructure assets.

\section{3. Research Methodology}

322 This research developed a new digital-twin-driven method for understanding design change 323 propagation in complex engineering systems at the asset level by integrating IFC and DSM. The 324 innovative digital-twin-driven DSM and associated design change propagation prediction method will 325 be developed and validated based on three interconnected steps, namely, (1) the development of DSM 326 at the asset level, (2) design change propagation based on DSM and fuzzy linguistics, and (3) a case 327 study for validation (Figure 2). 


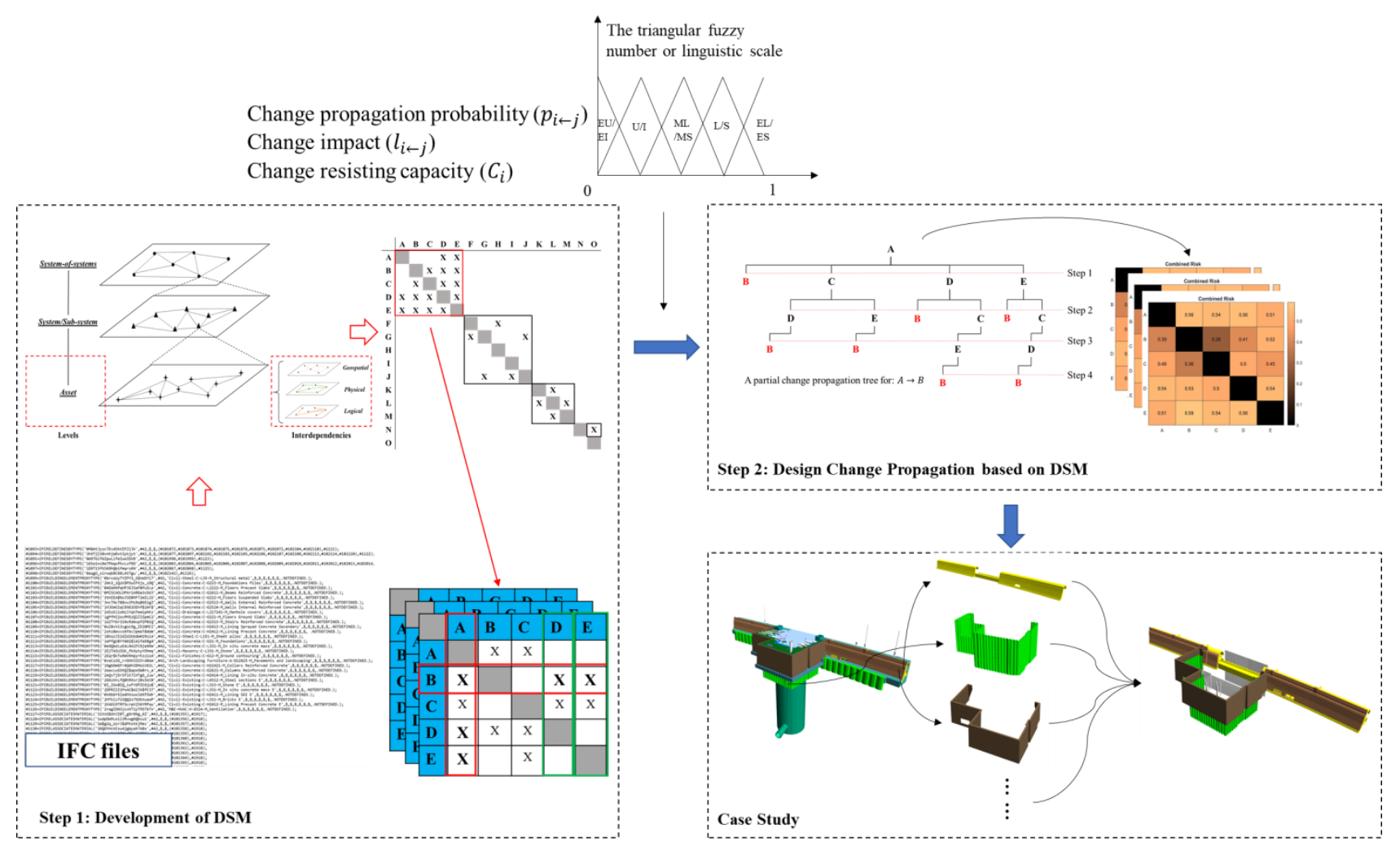

Figure 2. Research structure of design change propagation using DSM

330 The critical interdependencies of DSM at the asset level have first been proposed and defined 331 according to the IFC schema for design change management of complex engineering systems. In total, 332 three types of interdependency have been formally defined. The 9-Intersection Model (9-IM) based on 333 spatial algebra was used in this research to formally define the spatial topological interdependencies 334 contained in the digital twin model, which is useful when defining spatial topological 335 interdependencies in a BIM environment, including cases of solid-to-solid relationships (Borrmann 336 and Rank, 2009; Daum and Borrmann, 2014). The IfcRelationship entity and its subtypes were also 337 adopted in this research to handle non-spatial interdependencies between assets, which were the 338 abstract generalisation of all objectified relationships in IFC and can be sufficient for defining most 339 semantic interdependencies in practice (buildingSMART, 2019).

340 These three types of system interdependency at the asset level were further examined through focus 341 group meetings and a workshop. The monthly focus group meetings were held between the research 342 team and key stakeholders from the industry partner (i.e. the infrastructure mega-project) from 343 December 2018 to June 2019 at Imperial College London. Each meeting lasted for around 1 hour and 344 focused on defining, identifying and qualifying the critical interdependencies emerging in complex 345 engineering systems. One workshop with the wider community involved input from academia and 346 project managers and data scientists from the major infrastructure project and was held on $2^{\text {nd }}$ July 
3472019 at Imperial College London. It lasted for around four hours and mainly focused on evaluating, 348 modifying and verifying the findings.

349 Based on the developed digital-twin-driven DSM, the IGTA-Plus with suppressing multi-cluster 350 allocation (SMA) was then used to break up the large-scale DSMs into smaller sub-DSMs, i.e. modules 351 (Borjesson and Hölttä-Otto, 2012). The IGTA-Plus with SMA improvement was adopted in this 352 research due to its sound extension to IGTA and widely validated usefulness in the past decade 353 (Thebeau, 2001; Borjesson and Hölttä-Otto, 2012; Borjesson and Sellgren, 2013). This cluster analysis 354 was concerned with the grouping of elements into homogeneous modules based on their 355 interdependencies, which will maximise interactions within the modules while minimising the 356 interactions between modules (Michelena and Papalambros, 1995). Designers can, thus, focus only on 357 corresponding modules and changes within modules, simplifying the design architecture significantly 358 and improving the efficiency of computational procedures.

359 A novel hybrid approach has been further developed to predict design change propagation within 360 modules of complex engineering systems by integrating fuzzy linguistics, CPM and the load-capacity 361 model (Clarkson et al., 2004; Chen and Pan, 2016; Li et al., 2020). The risk-capacity model is one of 362 the most popular models to deal with the risk of change propagation in complex project networks, 363 which contains two elements: risk load and risk resisting capacity ( $\mathrm{Li}$ et al., 2020). When risk loads of 364 elements surpass their capacities, these elements will trigger the potential change in neighbouring 365 elements. However, such a model only focuses on the adjacent elements for the direct risk of change 366 propagation while ignoring the indirect risk. In this research, the CPM (Clarkson et al., 2004) was thus 367 integrated into the load-capacity model for calculating the combined risk of change propagation from 368 both direct and indirect elements. Fuzzy linguistics (Chen and Pan, 2016) was also adopted to deal 369 with uncertainty and minimise bias when collecting subjective data for qualifying the design change 370 propagation risks in focus group meetings. This novel hybrid approach first computed the risk load of 371 design change propagation for each element based on CPM, where the fuzzy linguistic scales were 372 used to estimate the change propagation probability $\left(p_{i \leftarrow j}\right)$ and change impact $\left(l_{i \leftarrow j}\right)$. It then identified 373 the critical design change paths in DSM based on the load-capacity model. The results were finally 374 visualised in a digital-twin-driven DSM for better understanding (as shown in Figure 2).

375 A tunnel section of a major infrastructure project in London was selected as a case study to validate 376 this developed approach for design change propagation using digital-twin-driven DSM (Figure 2). A 377 tunnel section of the infrastructure mega-project was chosen with the following considerations in mind: 378 (1) the project is representative by its complexity, importance and size. It involves a major ongoing 379 intervention in London, developing an infrastructure that crosses or impinges on a range of existing 
infrastructures; (2) there has been intensive use of digital modelling in this project, with operational models driving design decisions, as well as an emergent set of increasingly sophisticated modelling practices developing over time (Whyte et al., 2019); and (3) the tunnel section is a sub-system level model where the volume of data is appropriate to conduct analyses at the asset level. The digital twin model and drawings of the tunnel section were collected from the project management team, and the parameters related to design change parameters were collected from experts during focus group meetings and examined at the workshop. These parameters included (1) change propagation probability $\left(p_{i \leftarrow j}\right),(2)$ change impact $\left(l_{i \leftarrow j}\right)$, and (3) change resisting capacity $\left(C_{i}\right)$.

\section{Development and Modularity of Digital-twin-driven DSM}

Based on the IFC files converted from digital models, the geometric and semantic information can be extracted for defining and identifying the elements and system interdependencies, which can finally generate the required DSMs at the asset level.

The elements have been defined as the assets of infrastructures in this research, which can be directly identified through mining the IFC files or using BIM Views engine in BIMserver. For example, the assets 'Civil Concrete: C-G215-M Foundations Piles' with different globally unique identifiers can be identified directly in the definition of IfcBuildingElementProxy (Figure 3).

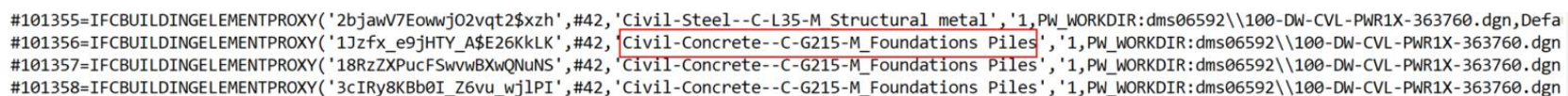

Figure 3. Example of identifying DSM elements in IFC file

398 The system interdependencies are classified based on the work of Rinaldi et al. (2001), where three 399 types of interdependency have been defined, including geospatial, physical and logical 400 interdependencies (Table 4). The cyber interdependencies are ignored here because the behaviours of 401 information exchange are beyond the scope of this research, which focuses instead on the design of 402 infrastructures from the perspective of civil engineering.

403 Table 4. Definitions of interdependencies for digital-twin-driven DSM at the asset level

\begin{tabular}{|c|c|c|c|c|}
\hline $\begin{array}{l}\text { Interdependency } \\
\text { types }\end{array}$ & Sub-types & Definitions & $\begin{array}{l}\text { Demonstrations in digital } \\
\text { twins }\end{array}$ & References \\
\hline Geospatial & & $\begin{array}{l}\text { The physical adjacency or } \\
\text { topological relationship } \\
\text { between assets. }\end{array}$ & $\begin{array}{l}\text { Disjoint, Inside, Equal, } \\
\text { Touch, Contain, Overlap, } \\
\text { Cover, CoveredBy }\end{array}$ & $\begin{array}{l}\text { Borrmann and Rank, } \\
\text { 2009; buildingSMART, } \\
2019\end{array}$ \\
\hline Physical & & $\begin{array}{l}\text { An objectified relationship } \\
\text { between a material } \\
\text { definition and elements or } \\
\text { element types to which this } \\
\text { material definition applies }\end{array}$ & IfcRelAssociatesMaterial & $\begin{array}{l}\text { Rinaldi et al., 2001; } \\
\text { Borrmann et al., 2015; } \\
\text { buildingSMART, 2019; } \\
\text { Goldbeck et al., } 2019\end{array}$ \\
\hline
\end{tabular}




\section{Resource neither a physical nor a}

\section{sharing} geospatial connection.

IfcRelAssignsToResource ${ }^{2}$

$405{ }^{2} \mathrm{An}$ objectified relationship assigning objects (IfcObject), acting as a resource usage or consumption, to a resource 406 (IfcResource).

407 Geospatial interdependencies occur when an environmental event can create state changes in entities, 408 which is usually identified as physical adjacency or a topological relationship between assets. The 9409 IM has been adopted in this research to define the geospatial interdependencies. The 9-IM calculus is 410 extended from 4-IM and based on the mathematical theories of algebraic topology and set topology 411 (Egenhofer and Franzosa, 1991). The geospatial interdependencies can, thus, be defined by the 412 intersection of the interior, exterior and boundary of two operands, where an intersection can yield an 413 empty $\varnothing$ or a non-empty set $\neg \varnothing$ in a $3 \times 3$ matrix to represent eight solid-solid relations in a digital 414 twin environment, as shown in eq. (1) (Daum and Borrmann, 2014):

$$
I=\left(\begin{array}{lll}
A^{\circ} \cap B^{\circ} & A^{\circ} \cap \partial B & A^{\circ} \cap B^{-} \\
\partial A \cap B^{\circ} & \partial A \cap \partial B & \partial A \cap B^{-} \\
A^{-} \cap B^{\circ} & A^{-} \cap \partial B & A^{-} \cap B^{-}
\end{array}\right)
$$

416 where $A^{\circ}$ and $B^{\circ}$ are the interiors; $\partial A$ and $\partial B$ are the boundaries; $A^{-}$and $B^{-}$are the exteriors 417 of the solids $A$ and $B$ respectively. These eight geospatial interdependencies include Disjoint, Inside, 418 Equal, Touching, Containing, Overlapping, Covering, and CoveredBy (Table 5).

419 Table 5. Definitions of the geospatial interdependencies by the 9-IM

\begin{tabular}{|c|c|c|c|c|c|c|c|c|c|}
\hline$A^{\circ} \cap B^{\circ}$ & $A^{\circ} \cap \partial B$ & $A^{\circ} \cap B^{-}$ & $\partial A \cap B^{\circ}$ & $\partial A \cap \partial B$ & $\partial A \cap B^{-}$ & $A^{-} \cap B^{\circ}$ & $A^{-} \cap \partial B$ & $A^{-} \cap B^{-}$ & \\
\hline$\emptyset$ & $\varnothing$ & $\neg \emptyset$ & $\varnothing$ & $\varnothing$ & $\neg \emptyset$ & $\neg \varnothing$ & $\neg \varnothing$ & $\neg \emptyset$ & Disjoint \\
\hline$\neg \emptyset$ & $\neg \emptyset$ & $\neg \varnothing$ & $\varnothing$ & $\varnothing$ & $\neg \varnothing$ & $\varnothing$ & $\varnothing$ & $\neg \emptyset$ & Inside/ \\
\hline$\neg \varnothing$ & $\varnothing$ & $\varnothing$ & $\varnothing$ & $\neg \varnothing$ & $\varnothing$ & $\varnothing$ & $\varnothing$ & $\neg \emptyset$ & Equal \\
\hline$\emptyset$ & $\varnothing$ & $\neg \emptyset$ & $\emptyset$ & $\neg \varnothing$ & $\neg \emptyset$ & $\neg \varnothing$ & $\neg \varnothing$ & $\neg \emptyset$ & Touch \\
\hline$\neg \varnothing$ & $\neg \varnothing$ & $\neg \emptyset$ & $\neg \varnothing$ & $\neg \varnothing$ & $\neg \emptyset$ & $\neg \varnothing$ & $\neg \varnothing$ & $\neg \emptyset$ & Overlap \\
\hline$\neg \varnothing$ & $\neg \emptyset$ & $\neg \emptyset$ & $\varnothing$ & $\neg \varnothing$ & $\neg \varnothing$ & $\varnothing$ & $\varnothing$ & $\neg \varnothing$ & $\begin{array}{l}\text { Cover/ } \\
\text { CoveredBy }\end{array}$ \\
\hline
\end{tabular}

The physical interdependencies represent the relationships between elements via material, which can

421 be identified from IFC files using IfcRelAssociatesMaterial (Rinaldi et al., 2001). For example, the

422 IfcRelAssociatesMaterial denotes that the physical interdependencies occur between elements 423 \#101355 and \#101853 sharing the same type of material \#1917 'C-L35-M_Structural metal', where 424 the material change of one element will affect usage of the material in the other element (Figure 4). 
427 The logical interdependencies represent the functional relationships, or not geospatial or physical 428 connections (Rinaldi et al., 2001; Goldbeck et al., 2019). Two sub-types of logical interdependencies 429 have been defined in this research, including grouping and resource sharing. The grouping 430 interdependencies are essential in identifying the interactive elements (i.e. IfcObject) under a logical 431 aggregation (i.e. IfcGroup), to provide specific functions, where the entity IfcRelAssignsToGroup can 432 be adopted to extract such interdependencies. For example, the IfcRelAssignsToGroup assigns objects 433 (i.e. IfcObject \#575641, \#575667 etc.) to a group (i.e. IfcGroup \#1188039) for lighting, where the 434 functional change in one object will affect the functions of other objects in this group. The resource 435 sharing interdependencies define the logical relationships of objects (i.e. IfcObject) in resource (i.e. 436 IfcResource) assignment, where the resources contain the costs, schedules, and other impacts from the 437 use of a thing in a process except the materials. For example, the objects will interact logically if they 438 share the budget, where the cost change in one object will affect the budget of other objects.

Figure 5. Example of logical interdependencies (Grouping) in IFC file

With the digital-twin-driven DSM developed, the IGTA-Plus is then adopted to decompose the largescale DSMs into modular configurations, which will cluster a square matrix by moving elements from one cluster to another while minimising the interactions between modules and maximising the interactions within the modules.

To apply the IGTA-Plus, each element is initially and randomly placed in a module. Then the total coordination cost TotalCost of DSM is calculated out as the criteria to determine whether the DSM is clustered optimally by (Thebeau, 2001):

$$
\text { ExtraClusterCost }=\sum_{i, k \notin \text { Cluster }_{j}}(D S M(i, k)+D S M(k, i)) \times D S M S i z e^{\text {powcc }}
$$

$$
\text { IntraClusterCost }=\sum_{j=1}^{n_{\text {cluster }}}\left(\text { ClusterSize }_{j}^{\text {powcc }} \sum_{i, k \in \text { Cluster }_{j}}(\operatorname{DSM}(i, k)+\operatorname{DSM}(k, i))\right)
$$
within a module; ExtraClusterCost is the cost of interdependencies outside any module; 
$453 \operatorname{DSM}(i, k)$ and $\operatorname{DSM}(k, i)$ are the interdependencies between the $i$ th and $j$ th elements; DSMSize 454 is the number of elements in the DSM; ClusterSize $j$ is the number of elements within $j$ th module; 455 powcc is the penalty of the size of modules and powcc = 1 in most cases (Thebeau, 2001).

456 It will then select an element randomly from an existing module and determine whether there is another 457 module with a better fit, where the degree of fit can be calculated out by the ClusterBid (Thebeau, 458 2001):

$$
\text { ClusterBid }_{j}=\frac{\text { inout }_{j}^{\text {powdep }}}{\text { ClusterSize }_{j}^{\text {powbid }}}
$$

where inout is the sum of DSM interdependencies between the chosen element and every other in the $j$ th module; powdep is the exponential to emphasise interdependencies and powdep $=4$ in most cases; powbid is the exponential to penalise size of the $j$ th module and powbid $=1$ in most cases. The selected element will be moved to the module with the highest value of ClusterBid . When

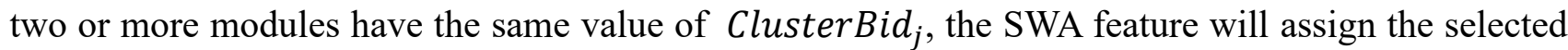
element randomly to one of these modules (Borjesson and Hölttä-Otto, 2012). Finally, Totalcost will be updated accordingly and the procedure will be repeated for a new randomly selected element until the value of TotalCost cannot be made any lower.

\section{Design Change Propagation Prediction based on DSM}

469 Based on the developed DSM, the designers need only focus on the essential interdependencies within 470 the clustered modules while ignoring the non-essential interdependencies outside the modules for high 471 efficiency and acceptable accuracy in design change propagation prediction.

472 The design change propagation can be traced and predicted properly based on change propagation 473 probability and change impact (Fu et al., 2012; Li et al., 2020). The change propagation probability 474 measures the likelihood of a change of one element directly causing a change of others, and the change 475 impact measures how significantly the impacted elements will change. Both can be measured using 476 the 5-point triangular fuzzy linguistic scales (Table 6).

477 Table 6. Triangular fuzzy linguistic scales

\begin{tabular}{lll}
\hline $\begin{array}{l}\text { Linguistic scale for change } \\
\text { propagation probability }\end{array}$ & Linguistic scale for change impact & Triangular fuzzy numbers \\
\hline Extremely unlikely (EU) & Extremely insignificant (EI) & $(0,0,0.25)$ \\
Unlikely (U) & Insignificant (I) & $(0,0.25,0.50)$ \\
Moderately likely (ML) & Moderately significant (MS) & $(0.25,0.50,0.75)$ \\
Likely (L) & Significant (S) & $(0.50,0.75,1)$ \\
Extremely likely (EL) & Extremely significant (ES) & $(0.75,1,1)$ \\
\hline
\end{tabular}


479 The arithmetic of two triangular fuzzy numbers $\tilde{A}_{1}=\left(l_{1}, m_{1}, u_{1}\right)$ and $\tilde{A}_{2}=\left(l_{2}, m_{2}, u_{2}\right)$ are as follows (Chen and Pan, 2016):

481

$$
\begin{gathered}
\tilde{A}_{1}+\tilde{A}_{2}=\left(l_{1}+l_{2}, m_{1}+m_{2}, u_{1}+u_{2}\right) \\
\tilde{A}_{1}-\tilde{A}_{2}=\left(l_{1}-u_{2}, m_{1}-m_{2}, u_{1}-l_{2}\right) \\
\tilde{A}_{1} \times \tilde{A}_{2}=\left(l_{1} \times l_{2}, m_{1} \times m_{2}, u_{1} \times u_{2}\right)\left(l_{i}>0, m_{i}>0, u_{i}>0\right) \\
\tilde{A}_{1} / \tilde{A}_{2}=\left(l_{1} / u_{2}, m_{1} / m_{2}, u_{1} / l_{2}\right)\left(l_{i}>0, m_{i}>0, u_{i}>0\right)
\end{gathered}
$$

According to the load-capacity model, each element in DSM for complex engineering systems embodies the maximum capacity to resist design change. When the risk load of design change propagation is higher, the elements will need to be paid more attention to for design changes. Specifically, the design of the element must be changed when the risk load exceeds the capacity:

$$
s_{i \leftarrow j}=\left\{\begin{array}{l}
0, R_{i \leftarrow j} \leq C_{i} \\
1, R_{i \leftarrow j}>C_{i}
\end{array}\right.
$$

where $s_{i \leftarrow j}$ is the state of the $i$ th element $\left(e_{i}\right)$ when impacted by the $j$ th element $\left(e_{j}\right), R_{i \leftarrow j}$ is the combined risk of change propagation from the $j$ th to $i$ th element, and $C_{i}$ is the change resisting capacity of $e_{i}$.

The risk of change propagation can be defined as the product of change propagation probability $\left(\tilde{p}_{i \leftarrow j}\right)$ and change impact $\left(\tilde{l}_{i \leftarrow j}\right)$ using triangular fuzzy numbers (Fu et al., 2012; Li et al., 2020):

$$
\tilde{r}_{i \leftarrow j}=\tilde{p}_{i \leftarrow j} \times \tilde{l}_{i \leftarrow j}
$$

Where $\tilde{r}_{i \leftarrow j}$ is the risk of change propagation from $e_{j}$ to $e_{i}$, and $\tilde{p}_{i \leftarrow j}$ and $\tilde{l}_{i \leftarrow j}$ are the probability and impact of change propagation from $e_{j}$ to $e_{j}$, respectively.

A predictive model for design change propagation should include such risks from both direct and indirect elements (Clarkson et al., 2004; Fu et al., 2012). The combination of these risks can be estimated through $\cap$ (AND) and $\cup(\mathrm{OR})$ operators:

$$
\begin{gathered}
\tilde{p}_{i \leftarrow j} \cap \tilde{p}_{r \leftarrow s}=\tilde{p}_{i \leftarrow j} \times \tilde{p}_{r \leftarrow s} \\
\tilde{p}_{i \leftarrow j} \cup \tilde{p}_{r \leftarrow s}=\tilde{p}_{i \leftarrow j}+\tilde{p}_{r \leftarrow s}-\left(\tilde{p}_{i \leftarrow j} \times \tilde{p}_{r \leftarrow s}\right)=I-\left(I-\tilde{p}_{i \leftarrow j}\right) \times\left(I-\tilde{p}_{r \leftarrow s}\right)
\end{gathered}
$$

where the risks of elements in the same branch (e.g., A-C-D-B in Figure 6) are combined by an 'AND' operator, while the risks of elements in different branches (e.g., C-D-B and D-B in Figure 6) are combined by an 'OR' operator. The combined risk of change propagation $R_{i \leftarrow j}$ can be calculated as 
the cumulative risk from both direct and indirect elements:

$$
\begin{aligned}
\tilde{r}_{i \leftarrow j}^{(m)}= & \left(\tilde{p}_{i \leftarrow m-1} \times \tilde{p}_{m-1 \leftarrow m-2} \times \cdots \times \tilde{p}_{2 \leftarrow 1} \times \tilde{p}_{1 \leftarrow j}\right) \times \tilde{l}_{i \leftarrow m-1} \\
& R\left[\tilde{R}_{i \leftarrow j}\right]_{N \times N}=\left[\tilde{R}_{i \leftarrow j}\right]_{N \times N}=\left[\sum_{m-1}^{N} \tilde{r}_{i \leftarrow j}^{(m)}\right]_{N \times N}
\end{aligned}
$$

509 where $m$ indicates that a design change from $e_{j}$ propagates to $e_{i}$ after $m$ transmission steps 510 (Figure 6). When $m=1, \tilde{r}_{i \leftarrow j}^{(1)}$ is the direct risk of change propagation. $\tilde{r}_{i \leftarrow j}^{(m)}$ is the indirect risk when $511 m \geq 1$. A practical limit of three or four steps is suggested for saving time with required accuracy, and 512 the routes returning to previously visited elements can be ignored for clarity and simplification 513 (Clarkson et al., 2004).

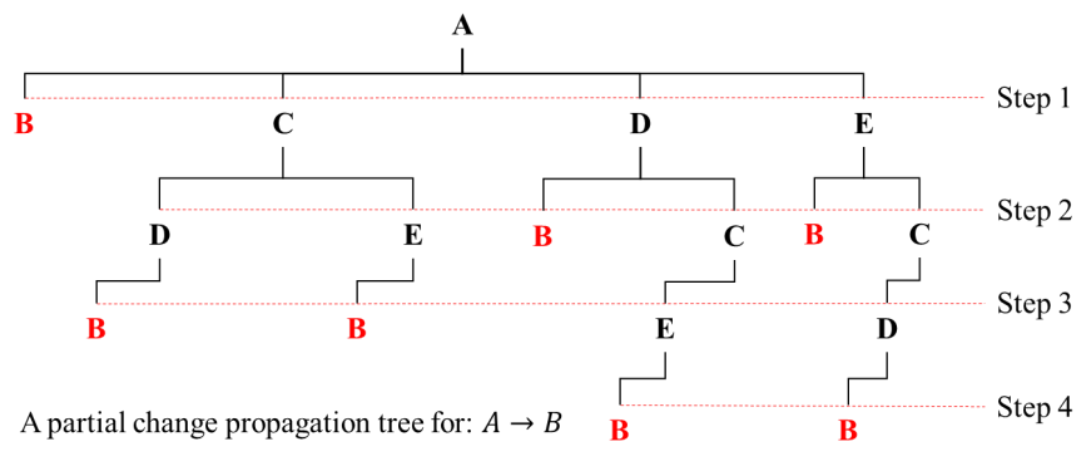

Figure 6. Design change propagation tree

516 When the risk is propagated to the element, its capacity of resisting change will decide whether this 517 element needs to be changed or not. The capacity of $i$ th element $\left(\tilde{C}_{i}\right)$ shows the design flexibility and 518 is related to the out-degree of the impacted element $\left(K_{i(o u t)}\right)$ and the average impact of all probable 519 change risks $\left(\overline{\tilde{L}}_{i}\right)$ (Pasqual and de Weck, 2012; Zhang and Yang, 2013; Li et al., 2020):

$$
\begin{gathered}
C\left[\tilde{C}_{i}\right]_{N}=\left[\tilde{C}_{i}\right]_{N}=\left[\alpha K_{i(\text { out })}^{\beta} \overline{\tilde{L}}_{i}\right]_{N} \\
\overline{\tilde{L}}_{i}=\sum_{j=1}^{M} \tilde{R}_{i \leftarrow j} / M
\end{gathered}
$$

522 where $\alpha$ and $\beta$ are adjustable parameters and $\alpha, \beta>0$. $K_{i \text { (out) }}$ represents the out-degree of the

523 element $e_{i}$, and $\overline{\tilde{L}}_{i}$ shows the average impact when upstream elements propagate change risks to the 524 element $e_{i}$. In this research, we fix $\alpha=0.1, \beta=1$ (Li et al., 2020).

525 After determining the risk load and resisting capacity, the triangular fuzzy numbers need to be de526 fuzzified into crisp numbers for comparison in eq. (11) and visualisation in DSM:

$$
x_{\text {defuzzified }}=\left[\left(u_{i}-l_{i}\right)+\left(m_{i}-l_{i}\right)\right] / 3+l_{i}
$$

\section{Case Study}

529 A tunnel section of a major infrastructure project in London was selected as a case study to validate 
530 this developed approach for design change propagation using a digital-twin-driven DSM (Figure 7).

531 This ongoing project is delivering a $25 \mathrm{~km}$ super sewer under the Thames that will prevent the tens of 532 millions of tonnes of pollution from entering the River Thames every year. This complex and important 533 infrastructure mega-project is being built across 24 construction sites/sections, spanning from Acton 534 in West London to Beckton in the East and will be completed in 2025.

535 With the digital model and drawings of this case project, the digital-twin-driven large-scale DSMs at 536 the asset level can be established based on IFC files and further clustered into modules using IGTA537 Plus. This research focused on just one of these modules in this case study to demonstrate and validate 538 the developed approach due to the limited data access and data confidentiality. However, it can be 539 representative to fully examine the usefulness in practice through generating the digital-twin-driven 540 DSM and predicting the design change propagation.

541 Based on IFC files of the tunnel section, the digital-twin-driven DSMs have been developed and 542 clustered, where the geospatial and physical interdependencies have been identified automatically 543 while the logical interdependencies were not defined in these IFC files (Figure 7). The five elements 544 have been clustered into one module in the geospatial DSM.

545 With this module of DSM generated (Figure 8(1)), the change propagation probability $\left(\tilde{p}_{i \leftarrow j}\right)$ and 546 change impact $\left(\tilde{l}_{i \leftarrow j}\right)$ were estimated using triangular fuzzy linguistic scales (Figure $8(2)$ ), where such 547 parameters were defined according to the literature review and authors' project experience in this 548 research for demonstration purpose only ( $\mathrm{Li}$ et al., 2020). Then using eq. (12-16) and eq. (19), the 549 combined risks of design change propagation were predicted and visualised in DSM (Figure 8(4)). 550 Finally, by comparing the change-resisting capacity (eq. (17-18)) and combined risk, the design 551 change propagation can be predicted and visualised (Figure 8(6)). For example, when the element $A$ 552 is changed, the combined risks of downstream elements $B, C, D, E$ exceed the change-resisting 553 capacities and such elements must be changed accordingly. 

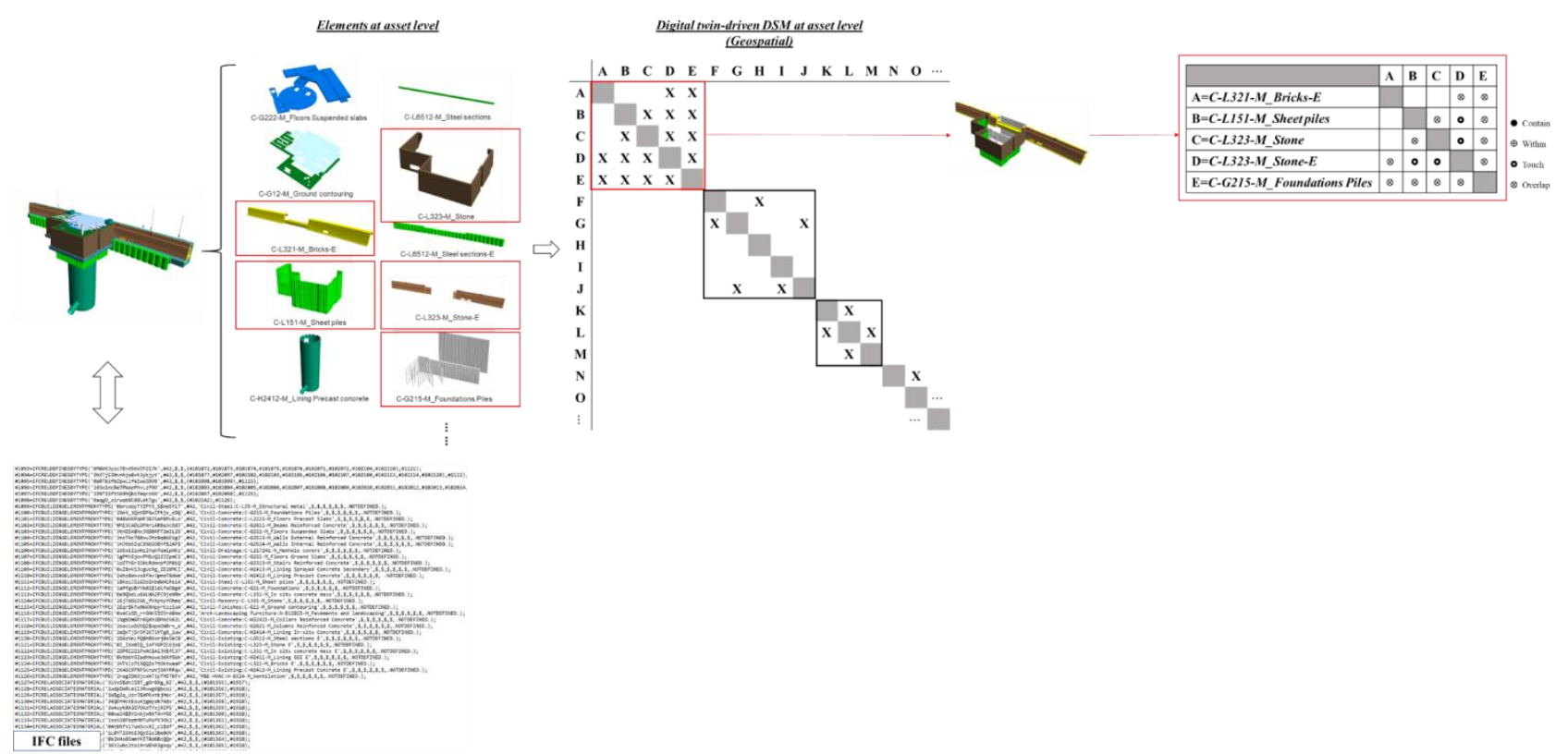

Figure 7. Generating digital-twin-driven DSM for tunnel section at the asset level

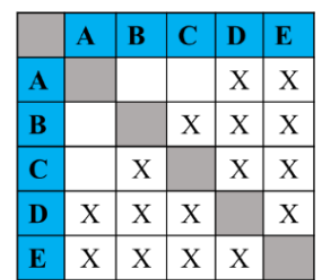

(1) Digital-DSM

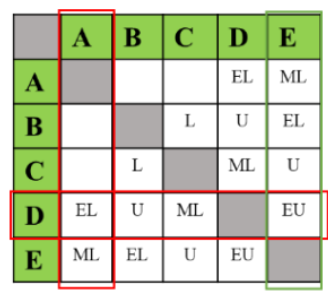

(2.1) Predicted change propagation probability

\begin{tabular}{|c|c||c|c|c|c|}
\hline & A & B & C & D & E \\
\hline A & & & & MS & S \\
\hline B & & & EI & I & MS \\
\hline C & & EI & & S & S \\
\hline D & MS & I & S & & ES \\
\hline E & S & MS & S & ES & \\
\hline
\end{tabular}
(2.2) Predicted change impact

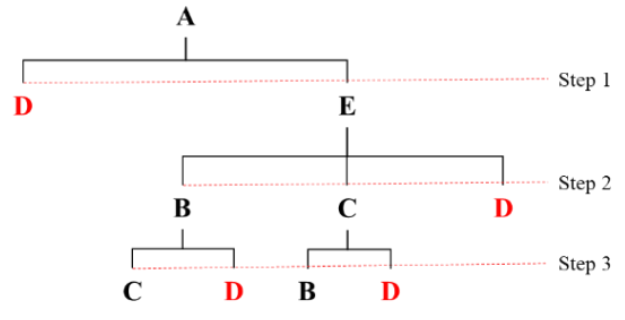

(3)A partial change propagation tree for: $A \rightarrow D$

$\uparrow$ The triangular fuzzy

number or linguistic scale

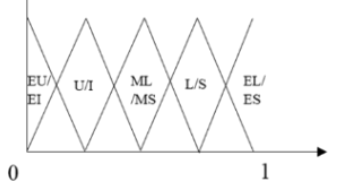

$x_{\text {defuzzified }}=\left[\left(u_{i}-l_{i}\right)+\left(m_{i}-l_{i}\right)\right] / 3+l_{i}$

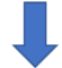

\begin{tabular}{|l|l|l|l|l|l|}
\hline & A & B & C & D & E \\
\hline A & & & & X & X \\
\hline B & & & X & X & X \\
\hline C & & X & & X & X \\
\hline D & X & X & X & & X \\
\hline E & X & X & X & X & \\
\hline
\end{tabular}

(6) Predictive changes propagated from $\mathbf{A}$
$\left(C_{i}\right)$
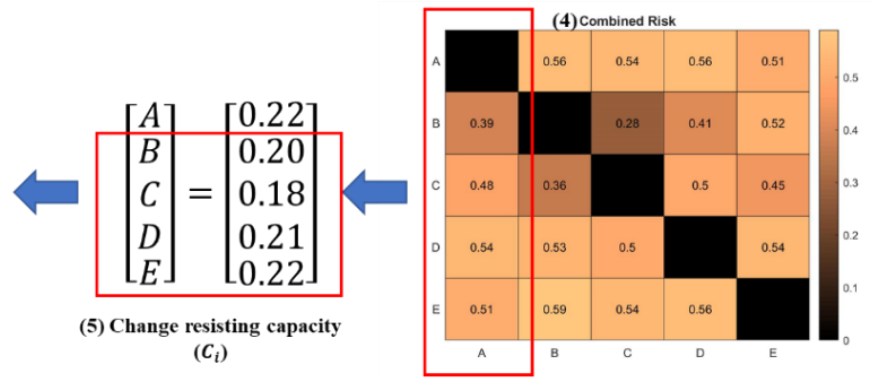

Figure 8. Design change propagation prediction based on a digital-twin-driven DSM

\section{Discussion}


This research contributes to the literature on the design change propagation of complex engineering systems by developing a digital solution based on digital-twin-driven DSM. Compared to previous methods, this developed approach can (1) comprehensively clarify the system interdependencies of infrastructures at the asset level; (2) generate and modularise the DSM in a more convenient way 564 through digital information and clustering analysis; and (3) provide a more reliable prediction of design 565 change propagation.

566 First, this research has extended the definitions of system interdependencies to the asset level of 567 infrastructures. Three types of system interdependency have been formally defined for infrastructures 568 at the asset level, including geospatial, physical and logical interdependencies (Table 4). Unlike 569 previous works (e.g. Jacob and Varghese, 2011, 2012; Saoud et al., 2017) which focused on limited 570 interdependencies (e.g. design sequence, spatial and analytical interdependencies), this approach 571 provided a more comprehensive insight into the complexity of infrastructures by defining three types 572 of system interdependency at the asset level, including geospatial, physical, and logical 573 interdependencies. These formally defined interdependencies can cover most interactions between 574 infrastructure assets.

575 It further identified the demonstrations of these defined interdependencies in digital twins, where the 576 9-IM based on spatial algebra has been adopted to define eight geospatial interdependencies and the 577 entity IfcRelationship and its subtypes, IfcRelAssociatesMaterial, IfcRelAssignsToGroup and 578 IfcRelAssignsToResource, which were adopted to handle physical and logical interdependencies, 579 respectively (Table 4). Based on these definitions and digital information, the DSMs at the asset level 580 have been developed automatically and conveniently for infrastructures by mining the IFC files or 581 using the BIM Views engine in the BIMserver. This digitally-driven method of generating DSMs can 582 be more time-saving and efficient than previous knowledge-driven methods (e.g. Clarkson et al., 2004; 583 Li et al., 2020) when dealing with complex engineering systems with thousands of elements. The 584 generated DSMs are usually large-scale due to the complexity of infrastructures. The clustering 585 analysis has been further conducted to modularise large-scale DSMs using IGTA-Plus, which is helpful 586 for designers to focus on design changes and estimate the strengths of interdependencies (i.e. change 587 propagation probability and impact) within decomposed small-scale modules.

588 Finally, the newly developed change propagation prediction method improved the robustness of 589 traditional CPM by integrating CPM with a load-capacity model. This method considered both the 590 combined risk load and resisting capacity to judge whether the design changes can be propagated, 591 which is more reliable than the CPM propagating the changes all the time (Clarkson et al., 2004; Fu et 592 al., 2012; Zhang and Yang et al., 2013; Li et al., 2020). The fuzzy linguistics has also been integrated 
593 into the prediction method to deal with the uncertainty and reduce the bias when estimating the

594 strengths of interdependencies, thereby improving the reliability of collected data and results.

\section{8. Conclusions}

596 Design change can introduce uncertainty and complexity into the design of complex engineering 597 systems, where tracking and predicting such change propagation is significant for project delivery with 598 high quality and data consistency. This research developed a new approach for predicting design 599 change propagation of complex engineering systems based on the use of a digital twin and DSM. It 600 first defined the digital-twin-driven DSM in terms of elements and interdependencies at the asset level, 601 providing both a theoretical understanding and a practical approach for integrating the digital twin 602 with a DSM. A clustering analysis based on IGTA-Plus was then conducted to decompose the large603 scale DSMs into modules for the convenience and efficiency of predicting design change propagation.

604 Then the design change propagation prediction method has been developed through integrating CPM, 605 load-capacity model and fuzzy linguistics. A case study of the tunnel section of an infrastructure mega606 project in London finally illustrated how the digital-twin-driven DSM at the asset level helped to 607 predict design change propagation in infrastructures.

608 This research makes a theoretical contribution to the body of knowledge by defining the system 609 interdependencies of a digital-twin-driven DSM at the asset level. It provides the first step towards 610 next-generation complex engineering systems by demonstrating the feasibility of using a digital twin 611 to generate new insights on systems relationships and interdependencies. The developed approach also 612 makes a practical contribution to generating a digital-twin-driven DSM and the attendant design 613 change management of complex engineering systems. Using spatial algebra and IFC schema, large614 scale DSMs can be generated from IFC files automatically and conveniently. The integration of 615 digitally-driven DSM and design change propagation analytics can further enable decision-makers to 616 rapidly understand interdependencies and design change propagation within modules and across their 617 boundaries in complex engineering systems.

618 Some limitations also need to be addressed in future research. First, the interdependencies defined 619 based on the IFC schema (Table 4) are limited. Second, the size of DSM generated in the case study is 620 limited by data access and confidentiality. Third, although the size of clustered modules is small, it is 621 still time-consuming for experts to estimate the interdependency strengths. Future research should be 622 conducted to address these limitations through (1) generalising the definition of digital-twin-driven 623 DSM not only based on IFC but considering the behaviour data from the digital twin; (2) validating 624 and tailoring the developed approach by generating and analysing large-scale DSMs with rich data 
625 from more case studies and feedback in the industry; and (3) integrating machine learning techniques

626 to provide risk estimations based on past project experience.

627

628

629

630

631

632

633

634

635

636

637

638

639

640

641

642

643

644

645

646

647

648

649

650

651

652

653

654

655

656

\section{Acknowledgements}

The work was supported by the Centre for Systems Engineering and Innovation (CSEI), Imperial College London, the Centre for Digital Built Britain (CDBB) General Research Project 2018-2019 'Analysing Systems Interdependencies using a Digital Twin', and the Lloyds Register Foundation/Data Centric Engineering Programme, The Alan Turing Institute.

\section{References}

Abdoli, S. and Kara, S. (2020). A modelling framework to support design of complex engineering systems in early design stages. Research in Engineering Design, 31(1), 25-52.

Austin, S., Baldwin, A., Li, B., and Waskett, P. (2000). Application of the analytical design planning technique to construction project management. Project Management Journal, 31(2), 48-59.

Bolton, A., Butler, L., Dabson, I., Enzer, M., Evans, M., Fenemore, T., Harradence, F., et al. (2018). Gemini Principles. (CDBB_REP_006)

Borjesson, F., and Hölttä-Otto, K. (2012) Improved clustering algorithm for design structure matrix. Proceedings of the ASME 2012 International design engineering technical conferences and computers and information in engineering conference (IDETC/CIE 2012), August 12-15, Chicago, IL, USA.

Borjesson, F., and Sellgren, U. (2013). Fast Hybrid Genetic Clustering Algorithm for Design Structure Matrix. Proceedings of the ASME 2013 International Design Engineering Technical Conferences and Computers and Information in Engineering Conference (IDETC/CIE 2013), August 7 , Portland, OR, USA.

Borrmann, A., König, M., Koch, C., and Beetz, J. (2015). Building Information Modeling: Technology Foundations and Industry Practice. Springer, Cham.

Borrmann, A., and Rank, E. (2009). Topological analysis of 3D building models using a spatial query language. Advanced Engineering Informatics, 23(4), 370-385.

Brady, T. K. (2002). Utilization of dependency structure matrix analysis to assess complex project designs. In: ASME 2002 international design engineering technical conferences and computers and information in engineering conference. American Society of Mechanical Engineers, 231-240

Browning, T. R. (2001). Applying the design structure matrix to system decomposition and integration problems: a review and new directions. IEEE Transactions on Engineering management, 48(3), 292-306. 
buildingSMART.

(2019).

Industry

Foundation

Classes

Version <https://standards.buildingsmart.org/IFC/DEV/IFC4_2/FINAL/HTML/> (Jul. 16, 2019)

Chen, L., Lu, Q., and Zhao, X. (2020). Rethinking the construction schedule risk of infrastructure 36(5), 04020066.

Chen, L. and Pan, W. (2016). BIM-aided variable fuzzy multi-criteria decision making of low-carbon building measures selection. Sustainable Cities and Society, 27, 222-232.

Chen, L. and Whyte, J. (2020). Analysing interdependencies of complex engineering systems using a digital-twin-driven design structure matrix. In Construction Research Congress 2020: Computer Applications, Reston, VA: American Society of Civil Engineers, 417-426.

Chou, C. C. and Tseng, S. M. (2010). Collection and analysis of critical infrastructure interdependency relationships. Journal of computing in civil engineering, 24(6), 539-547.

Clarkson, P. J., Simons, C., and Eckert, C. (2004). Predicting change propagation in complex design. J. Mech. Des., 126(5), 788-797.

Colombo, E. F., Cascini, G., and de Weck, O. L. (2015). Impact of architecture types and degree of modularity on change propagation indices. In DS 80-3 Proceedings of the 20th International Conference on Engineering Design (ICED 15) Vol 3: Organisation and Management, Milan, Italy, 27-30 July 2015, 187-198.

Daum, S., and Borrmann, A. (2014). Processing of topological BIM queries using boundary representation based methods. Advanced Engineering Informatics, 28(4), 272-286.

Davies, A. (2017). Projects: A Very Short Introduction, Oxford University Press.

Delany, S. (2019). "UNICLASS Classification” <https://toolkit.thenbs.com/articles/classification> (Jul. 16, 2019)

Dibley, M., Li, H., Rezgui, Y., and Miles, J. (2012). An ontology framework for intelligent sensorbased building monitoring. Automation in Construction, 28, 1-14.

Dudenhoeffer, D. D., Permann, M. R., Woolsey, S., Timpany, R., Miller, C., McDermott, A., and Manic, M. (2007). Interdependency modeling and emergency response. In Proceedings of the 2007 summer computer simulation conference, 1230-1237.

Eckert, C., Clarkson, P. J., and Zanker, W. (2004). Change and customisation in complex engineering domains. Research in engineering design, 15(1), 1-21.

Egenhofer, M. J., and Franzosa, R. D. (1991). Point-set topological spatial relations. International Journal of Geographical Information System, 5(2), 161-174.

Eusgeld, I., Nan, C., and Dietz, S. (2011). "System-of-systems” approach for interdependent critical infrastructures. Reliability Engineering \& System Safety, 96(6), 679-686. 
Fu, Y., Li, M., and Chen, F. (2012). Impact propagation and risk assessment of requirement changes for software development projects based on design structure matrix. International Journal of Project Management, 30(3), 363-373.

Giffin, M., de Weck, O., Bounova, G., Keller, R., Eckert, C., and Clarkson, P. J. (2009). Change propagation analysis in complex technical systems. Journal of Mechanical Design, 131(8).

Goldbeck, N., Angeloudis, P., and Ochieng, W. Y. (2019). Resilience assessment for interdependent urban infrastructure systems using dynamic network flow models. Reliability Engineering \& System Safety, 188, 62-79.

Gopsill, J. A., Snider, C., McMahon, C., and Hicks, B. (2016). Automatic generation of design structure matrices through the evolution of product models. AI EDAM, 30(4), 424-445.

Heracleous, C., Kolios, P., Panayiotou, C. G., Ellinas, G., and Polycarpou, M. M. (2017). Hybrid systems modeling for critical infrastructures interdependency analysis. Reliability Engineering \& System Safety, 165, 89-101.

Holden, R., Val, D. V., Burkhard, R., and Nodwell, S. (2013). A network flow model for interdependent infrastructures at the local scale. Safety Science, 53, 51-60.

Isaac, S., and Navon, R. (2013). A graph-based model for the identification of the impact of design changes. Automation in Construction, 31, 31-40.

ISO 16739-1:2018 (2018). Industry Foundation Classes (IFC) for Data Sharing in the Construction and Facility Management Industries.

Jacob, J., and Varghese, K. (2011). Integration of BIM and DSM to improve design process in building construction projects. In 13th International Dependency and Structure Modelling Conference, 1415 September, Cambridge, MASSACHUSETTS, USA.

Jacob, J., and Varghese, K. (2012). A model for product-process integration in the building industry using industry foundation classes and design structure matrix. In Construction Research Congress 2012: Construction Challenges in a Flat World, 21-23 May, West Lafayette, Indiana, USA.

Jacob, J., and Varghese, K. (2018). A framework for ad hoc information management for the building design process. Engineering, Construction and Architectural Management. 25(8), 1034-1052.

Jamshidi M. (1996). Large-Scale Systems: Modeling, Control and Fuzzy Logic. NJ: Prentice Hall.

Jeong, H. S., Qiao, J., Abraham, D. M., Lawley, M., Richard, J. P., and Yih, Y. (2006). Minimizing the consequences of intentional attack on water infrastructure. Computer-Aided Civil and Infrastructure Engineering, 21(2), 79-92.

Kocar, V., and Akgunduz, A. (2010). ADVICE: A virtual environment for Engineering Change Management. Computers in Industry, 61(1), 15-28.

Lambe, A. B., and Martins, J. R. (2012). Extensions to the design structure matrix for the description 
of multidisciplinary design, analysis, and optimization processes. Structural and Multidisciplinary Optimization, 46(2), 273-284.

Lee, H., Seol, H., Sung, N., Hong, Y. S., and Park, Y. (2010). An analytic network process approach to measuring design change impacts in modular products. Journal of Engineering Design, 21(1), 75-91.

Lee, J., and Hong, Y. S. (201PM7). Bayesian network approach to change propagation analysis.

Li, R., Yang, N., Zhang, Y., and Liu, H. (2020). Risk propagation and mitigation of design change for complex product development (CPD) projects based on multilayer network theory. Computers \& Industrial Engineering, 142, 106370.

Li, S. (2018). Guest Editorial: Special Section on Reliability, Resilience, and Prognostics Modeling of Complex Engineering Systems. IEEE Transactions on Reliability, 67(1), 2-2.

Ma, S., Jiang, Z., and Liu, W. (2017). A design change analysis model as a change impact analysis basis for semantic design change management. Proceedings of the Institution of Mechanical Engineers, Part C: Journal of Mechanical Engineering Science, 231(13), 2384-2397.

Mendonça, D. and Wallace, W. A. (2006). Impacts of the 2001 world trade center attack on New York city critical infrastructures. Journal of Infrastructure Systems, 12(4), 260-270.

Michelena, N. F., and Papalambros, P. Y. (1995). Optimal model-based decomposition of powertrain system design. Journal of Mechanical Design, 117(4), 499-505.

Pasqual, M. C., and de Weck, O. L. (2012). Multilayer network model for analysis and management of change propagation. Research in Engineering Design, 23(4), 305-328.

Pektas, S. T. (2010). The complementary use of the parameter-based design structure matrix and the IFC process models for integration in the construction industry. In The 12th International DSM Conference, 22-23 July, Cambridge, UK.

Pektaş, Ş. T., and Pultar, M. (2006). Modelling detailed information flows in building design with the parameter-based design structure matrix. Design Studies, 27(1), 99-122.

Pimmler, T. U., and Eppinger, S. D. (1994). Integration analysis of product decompositions. In ASME Design Theory and Methodology Conference, September, Minneapolis, MN, USA.

Prasad, A., and Jacob, J. (2018). A Framework for Incorporating Dependency Structure Matrix in Building Design Process. International Research Journal of Engineering and Technology, 5(4), 4938-4945.

Rinaldi, S. M., Peerenboom, J. P., and Kelly, T. K. (2001). Identifying, understanding, and analyzing critical infrastructure interdependencies. IEEE control systems magazine, 21(6), 11-25.

Saoud, L. A., Omran, J., Hassan, B., Vilutienè, T., and Kiaulakis, A. (2017). A method to predict 
change propagation within building information model. Journal of Civil Engineering and Management, 23(6), 836-846.

Senthilkumar, V., and Varghese, K. (2009). Structured methodology to formulate drawing dependency structure matrix for construction design. Architectural Engineering and Design Management, 5(4),

Tchana, Y., Ducellier, G., and Remy, S. (2019). Designing a unique Digital Twin for linear infrastructures lifecycle management. Procedia CIRP, 84, 545-549.

Terkaj, W., and Šojić, A. (2015). Ontology-based representation of IFC EXPRESS rules: An enhancement of the ifcOWL ontology. Automation in Construction, 57, 188-201.

Thebeau R. E. (2001) Knowledge management of system interfaces and interactions for product development process. Master's thesis at Massachusetts Institute of Technology, System Design and Management Program.

Utne, I. B., Hokstad, P., and Vatn, J. (2011). A method for risk modeling of interdependencies in critical infrastructures. Reliability Engineering \& System Safety, 96(6), 671-678.

Wang, S., Hong, L., and Chen, X. (2012). Vulnerability analysis of interdependent infrastructure systems: A methodological framework. Physica A: Statistical Mechanics and its applications, 391(11), 3323-3335.

Whyte, J. (2019). How Digital Information Transforms Project Delivery Models. Project Management Journal, 50(2), 177-194.

Whyte, J., Coca, D., Fitzgerald, J., Mayfield, M., Pierce, K., Shah, N., Chen, L., et al. (2019). Analysing Systems Interdependencies Using a Digital Twin. 2018/19 General Project funded by CDBB, Final Report.

Whyte, J., Stasis, A., and Lindkvist, C. (2016). Managing change in the delivery of complex projects: Configuration management, asset information and 'big data'. International Journal of Project Management, 34(2), 339-351.

Zhang, Y., and Yang, N. (2013). Research on robustness of R\&D network under cascading propagation of risk with gray attack information. Reliability Engineering \& System Safety, 117, 1-8.

Zhang, P. and Peeta, S. (2011). A generalized modeling framework to analyze interdependencies among infrastructure systems. Transportation Research Part B: Methodological, 45(3), 553-579.

Zhang, L., and Issa, R. R. (2013). Ontology-based partial building information model extraction. Journal of Computing in Civil Engineering, 27(6), 576-584.

Zhu, J. and Mostafavi, A. (2017). Performance assessment in complex engineering projects using a system-of-systems framework. IEEE Systems Journal, 12(1), 262-273.

Zimmerman, R. (2001). Social implications of infrastructure network interactions. Journal of Urban 
Technology, 8(3), 97-119. 